\title{
Quality decisions from physicians' shared knowledge in virtual communities
}

\author{
Anjum Razzaque ${ }^{\mathrm{a}}$, Tillal Eldabib and Weifeng Chen ${ }^{\mathrm{c}}$ \\ ${ }^{a}$ Management Information Systems, Ahlia University, Manama, Bahrain; ${ }^{b}$ Department of Business Transformation, University of Surrey,
} Guildford, UK; 'Brunel Business School, Brunel University, Uxbridge, UK

\begin{abstract}
Physicians strive to reconcile decisions with social capital (SC) within virtual communities explained by Social Capital Theory (SCT)'s dimensions - identity, social interaction ties, and shared language. This study's model with six hypotheses, assesses trust's moderation between SC and knowledge sharing. Knowledge sharing enhances the quality of decision-making. A questionnaire got 204 response from US virtual community physicians. Confirmatory Factor Analysis and Structural Equation Modelling revealed that identity negatively influences shared language, interaction ties cannot influence knowledge sharing, though this behaviour enhances the quality of decision-making. Trust positively influences identity and quality in shared knowledge, but negatively influences this behaviour and shared language. Quality in shared knowledge partially mediates identity and quality of decision-making and fully mediates shared language and quality of decision-making. Theoretical and practical implications are reported in this first of its kind study assessing trust moderation and knowledge sharing mediation between SCT and quality of decision-making.
\end{abstract}

\section{Introduction}

Clinical decision-making requires evidenced rationale from shared experiences (Lin \& Chang, 2008; Magnier-Watanabe et al., 2010; Nemati et al., 2002). Physicians share knowledge on virtual communities, e.g., Facebook, to build the SC. Scholars doubt the authenticity of trust-based knowledge sharing for clinical decision-making (Alsharo et al., 2017; Lin et al., 2016). According to Alsharo et al., trust enriches virtual collaborations for synergic outcomes, an unclear role for physicians who virtually share knowledge for informed decision-making (Razzaque \& Eldabi, 2018).

One stream of research, SC theory (SCT), empirically confirms that SC positively influences virtually shared knowledge (e.g., Alsharo et al., 2017; Chang et al., 2011; Chiu et al., 2006; Fan \& Wu, 2011; Lin

et al., 2016; Tsai \& Ghoshal, 1998) through SCT's structural dimension (social interaction ties), the relational dimension (trust, identity, and norms of reciprocity), and the cognitive dimension (shared language and shared vision) (Lin et al., 2016). Another stream of research empirically confirms that quality in shared knowledge influences quality of deci-

sion-making (e.g., Han et al., 2010; Lin \& Chang, 2008). However, there is sparse research done to assess

the effect and, therefore, scant evidence found for positive effect of physicians' virtual communities who share SC and quality knowledge to enhance the quality of medical decisions. There is a need to assess the effect of:
(1) SC on quality in the shared knowledge,

(2) SC on quality in the shared knowledge moderated by trust, a phenomenon empirically confirmed by Song and Phang (2016), Khvatova et al. (2016), and Lefebvre et al. (2016),

(3) quality in the shared knowledge on quality of decision-making, and

(4) mediation of quality in the shared knowledge between SC and quality of decision-making.

The model (Figure 1), is the first of its kind, to demonstrate how quality in shared knowledge mediates and trust moderates to enhance physicians' SC to make quality decisions in virtual environments. Not all of SCT's factors are assessed by this model because scholars assessing the influence of SC on virtually the shared knowledge found its influence on the relationships of trust and quality of the shared knowledge, norms of reciprocity and quality of the shared knowledge, and shared vision and quality in shared knowledge to be non-significant (e.g., Chiu et al., 2006; Tsai \& Ghoshal, 1998). Also, no evidence can be inferred from literature for the influences of the norms of reciprocity and shared vision for virtually sharing quality knowledge for medical decision-making inn virtual-community. For this reason, and since Fahey et al. (2007) empirically confirmed that norm-ofreciprocity devalues voluntary virtual knowledge sharing, these two variables were excluded.

Such holistic investigation confirms the importance of physicians' virtual sharing of quality knowledge for decision-making in stemming the rot in the quality of 


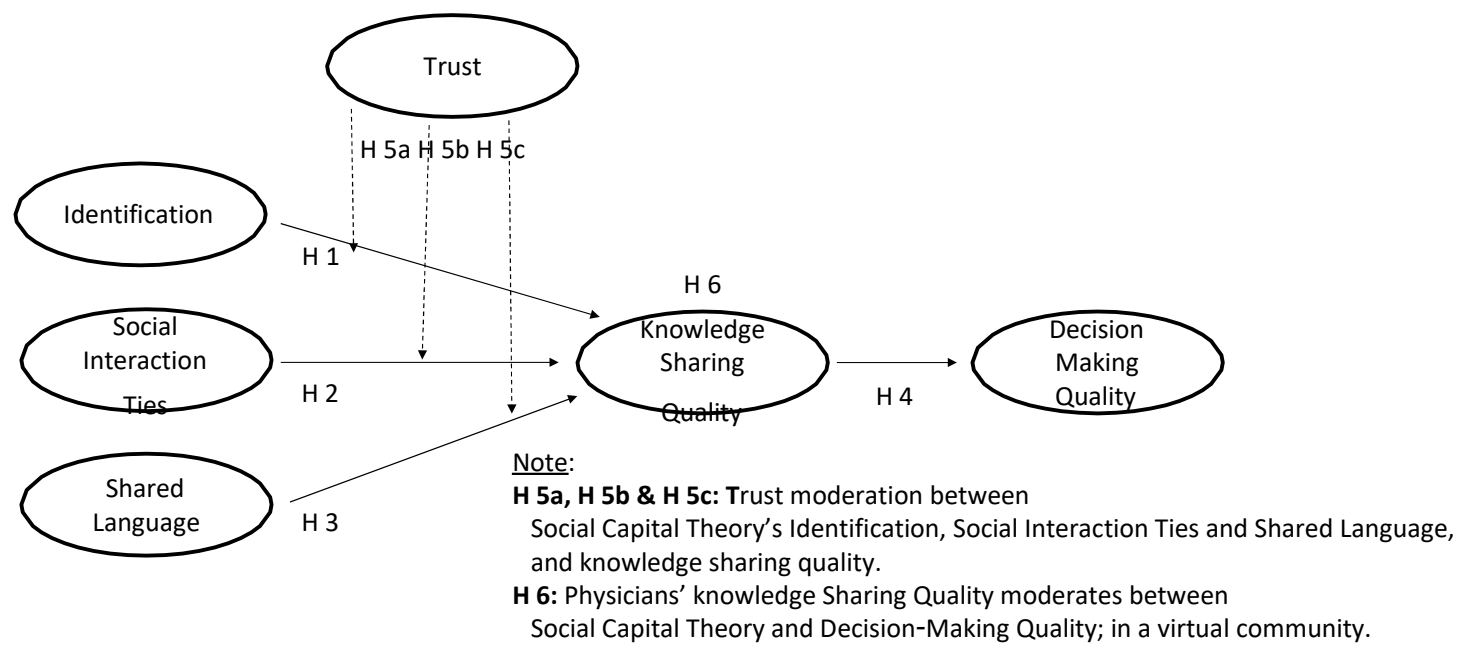

Figure 1. Research model.

healthcare service, which was evidenced by increasing annual incidence of diagnostic errors causing patient's deaths (Razzaque \& Eldabi, 2018, 2015). Section 2 critiques the literature, explaining the role of virtualcommunity SC in ensuring the quality of the shared knowledge, and the role of quality in shared knowledge on quality of decision-making; the moderating and enhancing role of trust on SC for knowledge sharing. Section 3 proposes six hypotheses (Figure 1) to build a theory. Section 4 describes this study's research methodology. Section 5 shows large data analysis revealing the questionnaire's reliability and validity. Section 6 discusses the findings and implication, and Section 7 presents the conclusion.

\section{Theoretical background}

\subsection{Comprehending quality of knowledge sharing through social capital theory}

Generally, several disciplines prove that the SC assets reside within individual/communal relations (Razzaque \& Eldabi, 2015). The motivation for personal gain inspires knowledge sharing. According to the applied theory of collective action; SC influences knowledge sharing without immediate reciprocity (Widén-Wulff \& Ginman, 2004). Many scholars, investigating SC and knowledge sharing, confirm that SC empowers organisational gain (Nahapiet \& Ghoshal, 1998). Tsai \& Ghoshal assessed the effect of SCT's structural dimension on the cognitive dimension, and the role of these two on the relationaldimension, revealing the empowering influence of interaction-ties and trust on knowledge sharing and innovation. Chiu et al. (2006) assessed virtual SC for outcome expectations during knowledge sharing and inferred that community members' identities and reciprocity encourage knowledge sharing. Chang and Chuang (2011) empirically inferred that nurses' trust and shared vision facilitate knowledge sharing for improving patients' safety. Fan and Wu (2011) metaanalysis assessing SC for knowledge sharing outcomes revealed reciprocity, identity, trust, and common language as influential for the intention of knowledge sharing. Chang and Chuang (2011) assessed SC and the motivations for knowledge sharing when moderated by participation and confirmed SC's and motivation's empowering role in the intent of knowledge sharing. Hung et al. (2011) list a few studies assessing $\mathrm{SC}$ influence on knowledge sharing.

Nov et al. (2012) re-assessed the influence of outcome expectations and SC on meta-knowledge, confirming its use for meta-knowledge. Yu et al. (2013) assessed the influence of SC of senior managers' in teams, and as individuals, on the shared knowledge in nine Chinese organisations revealing that team's SC motivates group knowledge sharing. Aslam et al. (2013) re-assessed the role of SC on the sharing of knowledge to apprehend how knowledge sharing affects academic performance, revealing that SCT's relational and cognitive dimensions, but not the structural dimension, influence knowledge sharing; Xiang et al. (2013) revealed the vitality of SC for improving team performance through knowledge sharing.

Choi (2016) assessed employees' on/offline US-federal -agencies' interactions motivated through reciprocity, trust, and outcome expectations from =knowledge sharing; revealing that reciprocity mediated interactions, trust, and expectations, but was non-influential for group knowledge sharing. Further, interactions build trust and reciprocity, and inspire knowledge sharing, though outcome expectations cannot influence knowledge sharing. Chumg et al. (2016) inferred that supportive and innovative culture facilitates employees' identity to support knowledge sharing. Lefebvre et al. (2016) reassessed the effect of the SC of 16 European e-learningnetworks on knowledge sharing, revealing that social interaction ties build common vision and language for 
trustworthy knowledge sharing. Dijk et al. (2016)'s assessment of SC's influence on knowledge sharing in Euro-Asian global construction firm's teams, confirmed that SC stimulates knowledge sharing.

Bakker et al. (2006) assessed trust's influence on knowledge sharing in new product-development projects revealing that faith poorly predicts knowledge sharing, meaning that trust is not vital for knowledge sharing. W.-L. Wu and Lee (2016) assessed SC at a group-level rather than individual-level (as a common empirical trait), indicating group insertions influence trust and knowledge sharing. Smith (2017) assessed how interactions affect the attitude for the sharing of tacit knowledge, when mediated by reciprocity; inferring that social interaction ties influence the sharing of tacit knowledge.

\subsection{Sharing quality knowledge for making quality decisions}

Patientcare involves three decisions-making styles: (1) paternalistic decision-making (doctor decides), shared decision-making (doctor and patient decide), and informed quality of decision-making (patient decides the treatment) (Puschner et al., 2010). Various studies labelled decision-making as knowledge-shared decision-making, treatment decision-making, collaborative decision-making, participative decision-making, or shared decision-making (Puschner et al., 2010). Knowledge-shared decisions are well-thought-out and time-consuming, occurring from the shared knowledge (Roberts, 2006). Treatment-based decision-making occurs during problem-solving and helps reduce diagnostic errors and make better decision (Puschner et al., 2010). This is an important finding since Makary's (2018) reported that annually, 250,000 patients die due to medical errors in the US alone. Additionally, virtualcommunity decisions are not only treatment decisions, shared decisions, participative decisions, or knowledgeshared decisions but are a virtual blend inspired from shared knowledge (Roberts, 2006).

Lin and Chang (2008) assessed and revealed sources, receivers, and contexts, as influential factors for sharing knowledge for improving the quality of decisionmaking, in a Chinese hospital. Han et al. (2010) assessed the effect and revealed that collaborative-participation develops a commitment to sharing knowledge. Alby et al. (2015) assessed and infrared that collaborative and informed decision-making is possible from collaborative knowledge sharing. Garcia-Perez et al. (2015) inquired and revealed that collaboration inspires knowledge sharing among British railway safety regulators, confirming that collaboration inspires knowledge sharing for quality of decision-making. Pinheiro et al.'s (2016) assessed practices of health-based ISs for decision-making, suggesting that strengthened culture facilitates such ISs for knowledge-shared decision-making.
André et al. (2017)'s social network analysis exploring Swedish foresters' knowledge-shared decision-making dialogues showed knowledge sharing during low network ties, inferring that interaction ties are crucial for knowledge-shared decision-making.

\subsection{Trust moderates between the social capital of assets and the sharing of knowledge behaviour, for enhancing the quality of decision-making}

Several researchers empirically assessed the role of SCT on knowledge sharing. Others assessed the role of knowledge sharing on decision-making. To-date research ignores participants' trust-regulated identity, interactions, and common language in virtual knowledgeshared decision-making, though interaction, common language, trust, and identity motivate knowledgeshared decision-making (Lefebvre et al., 2016). To-date research did not blend the two research streams to investigate the mediatory role of knowledge sharing between SCT and quality of decision-making to learn how trust beneficially regulates the quality of virtual knowledge-shared decision-making. This despite the fact that interaction-ties, common language, trust, and identity enable evidence-informed decisions by employing knowledge management tools, e.g., electronic health records and knowledge sharing through e-Health solutions (Schuele et al., 2015). To date, no scholar has empirically investigated virtual-community members' trust as a moderator for identities, interaction ties, and common language for improved quality in shared knowledge for improving the quality of decisionmaking. Therefore, this study aims to assess the effect of knowledge management tools (physicians' virtual communities) as a healthcare-research topic - constant involvement of quality knowledge-shared decisionmaking.

Trust's moderation, as this study's agenda, is significant as evidenced by literature. For instance, scholars investigated trust's moderation in virtual team's collaborative knowledge sharing (Pinjani \& Palvia, 2013) or investigated this as a moderator for the intention of adopting Business to Business (B2B) commerce in Jordan (Alsaad et al., 2017). Ho et al. (2018) assessed trust's mediation/moderation on Asian-Pacific firms' buyers' and suppliers' knowledge. Chen et al. (2015) assessed trust's moderation on the perceived benefits and risks of online users' behaviour. These few examples prove the paucity of an investigation into physicians' trust as a moderator between SC and quality in shared knowledge for the quality of decision-making in virtual communities.

\section{Research model}

Figure 1 depicts the relations of SCT's identity, social interaction ties and shared language with quality in 
shared knowledge, trust moderation between SCT factors with quality in shared knowledge, and quality in shared knowledge with quality of decision-making in the virtual community of physicians.

\subsection{Hypotheses building}

\subsubsection{Identity and quality in shared knowledge} Identity, SCT's relational dimension, reflects network ties to accomplish outcomes (Stets \& Serpe, 2016), and enrich mutual purpose. Employees identify through interactions, when expressing values, goals, andobjectives (Gossett, 2002) during knowledge-shared decision-making. The shared knowledge fosters member identity in communications during training (Gossett, 2002). In virtual communities, identities are outcomes of communicated values and beliefs, that facilitate the sharing of tacit/explicit knowledge (Hu \& Randel, 2014). Once community members identify with daily group-tasks, they begin to share knowledge, e.g., supervisors share technical information with employees/peers. Patients learn from, and support each other, by sharing practical advises as they identify with each other, since identity encourages virtual knowledge sharing and builds loyalty (Jiang et al., 2015; Mazanderani et al., 2012; song \& Phang, 2016). Similarly, instructors identify with students during teaching-learning via knowledge shared e-learning participation (Eisenberg \& Mattarelli, 2017). This argument proposes:

Hypothesis 1: Physicians' identity positively and significantly affects the quality of the knowledge they share in a virtual community.

\subsubsection{Social interaction ties and quality in the shared knowledge}

Social interaction ties reflect/provoke voluntary sharing of tacit/explicit knowledge (Hu \& Randel, 2014), which strengthen relations, so virtual-community physician-members can build SC. This occurs as they contribute opinions aiding quality of decisionmaking; ideal for clinical practices in tightly knit virtual networks, e.g., Twitter or LinkedIn, etc. (Chang \& Chuang, 2011; Fernandez-Perez et al., 2016; Komito, 2011; Magnier-Watanabe et al., 2010; Nicolini et al., 2008). Interaction ties in virtual communities, or infrequent interactions in communities, are weaker than in face-to-face interactions. Most scholars focused on strong ties networks while weak ties are scantily investigated. No wonder scholars doubt the quality of the shared knowledge in weak tie networks, that is, virtual communities (Homel et al., 2012; Park et al., 2014), which inspired our study. There is a strongly felt need to examine the relation between interaction ties and quality in knowledge sharing among virtual communities of physicians as scholars' findings in this respect are mixed. While FernandezPerez et al. (2016) rejected that social interaction ties facilitate knowledge sharing, Barroso-Castro et al. (2016) found that virtual interactions assist knowledge sharing. Furthermore, Mikovic et al. (2019) qualitatively confirmed that interaction-ties affected knowledge management processes. They examined the relationship between social network ties and application of knowledge in the SC, by interviewing 215 employees of European non-profit sector, and confirmed that SC, generated from internal organisational ties, substantially influenced knowledge-usage. This leads to:

Hypothesis 2: Physicians' social interaction ties positively and significantly affect the quality in shared knowledge in physician's virtual community.

\subsubsection{Shared language for quality of the shared knowledge}

Team-members efficiently collaborate while interacting to share tacit knowledge via a common technical language, i.e. shared vocabulary and vision communicated through commonly referred task jargons reflecting shared code for shared knowledge (Chiu et al., 2006; Warren et al., 2015). A significant relationship exists between shared language and shared tacit knowledge (Hu \& Randel, 2014; Jiang et al., 2015) was also confirmed by Mascia and Cicchetti (2011) who assessed managers' knowledge-sharing behaviours for ICT investment decisions, confirming that in such circumstances, knowledge sharing via common language enhances communication and interaction-ties (Chang \& Chuang, 2011). Though Ku (2019) assessed the effect of diversity on academically shared knowledge, from the lens of the SCT; confirming that SC influences quality knowledge sharing. Based on this argument, the following hypothesis can be made:

Hypothesis 3: Physicians' shared language positively and significantly affects their quality in shared knowledge in a virtual community.

\subsubsection{Quality in shared knowledge and quality of decision-making}

Physicians make decisions in virtual networks virtually by sharing tacit knowledge through storytelling and opinion-sharing or by explicitly expressing the tacit knowledge in text messages, which is an immensely attractive platform for researchers to understand how knowledge-sharing harnesses learning and innovation (Hasan \& Crawford, 2007; Malgonde \& Bhattacherjee, 2014). Such communications are deposited as SC in virtual communities as tacit and explicit knowledge blend for effective decision-making (Mansingh et al., 2009). The healthcare sector can utilise virtual communities to unify fragmented 
knowledge to enable physicians to make knowledge shared and thus, evidence-based decisions (YousefiNooraie et al., 2012). Based on this argument,

Hypothesis 4: Physicians' quality in shared knowledge positively and significantly affects their medical quality of decision-making in a virtual community.

\subsection{Moderation of trust}

There is little research on the effect of trust on knowledge-sharing behaviour while there is interest in the mediating role of trust between the dimension of the SCT and knowledge-sharing behaviour (Yen et al., 2015). Yen et al. are among the few observant scholars to assess the mediating role of trust, though not Trust's moderating role, and evidencing the signs that trust in various circumstances/contexts does facilitate an influential relation between SCT and knowledge sharing. Though Yen et al.'s study assessed the role of trust from the lens of the Chinese tradition referred as "guanxi", the mediating role of trust causes the need to further assess the moderating role of trust, which this study explored with reference to healthcare sector.

\subsubsection{Trust's moderation between identity and quality in shared knowledge}

Research identifies two variants of virtual communities, knowledge-shared virtual communities, and support-based virtual communities. In both, participants share knowledge with those they socially identify with, and thus, support each other by sharing knowledge. During knowledge sharing, identity enhances problem-solving as each participant gains repute. In support-based virtual communities, chronic-disease patients emotionally support each other by sharing knowledge with those whom they begin to trust they become identified with each other through interactions. Since identity and trust significantly affect knowledge-sharing behaviour. Identity facilitates the shared knowledge, but a lack of trust hampers it (Eisenberg \& Mattarelli, 2017; Song \& Phang, 2016). After all, trust inspires the willingness to share knowledge through commitment and kindness. Members identify with each other through interaction and share knowledge to perceive self-worth in the group. Similarly, members identify as team players by sharing knowledge (Jiang et al., 2015). Such an explanation proves that identity with the virtual-community members' is critical for sharing knowledge. Identity is so vital that in culturally diverse team, the team members turn out to be less receptive to the shared knowledge even when collaborating in projects till they begin to identify with the team. This is like virtual-community patients, who once begin identifying with each other, start to share their illnesses and its associating experiences. Such a common trait is the bridge that enables them to value each other and makes them willing to share knowledge (Mazanderani et al., 2012). According to Hashim and Tan (2015) trust arising from identity and regular interactions encourage knowledge sharing. This phenomenon was empirically affirmed by Rosendaal and BijlsmaFrankema (2015): that trust within a team positively influences the team members to identify with each other so to indulge in sharing knowledge. But this relationship was affirmed through the mediating role of trust. Hence, this is a promising underpinning phenomenon that can be further investigated to understand how trust moderates to influence physicians' identity to enhance their knowledge-sharing behaviour within virtual environments. From this, we derive,

Hypothesis 5a: Physicians' trust moderates between the identification and virtual-community quality in shared knowledge, so the relationship is stronger with higher levels of trust, than with lower levels of trust.

\subsubsection{Trust moderates between social interaction ties and quality in shared knowledge}

Khvatova et al. (2016) investigated trust and interactions for the virtual sharing of knowledge, revealing that shared knowledge is an individual and a group resource that is voluntarily created during interactions. In a virtual community, trust significantly motivates interactions for sharing knowledge through reciprocity, i.e., when parties develop mutual trust. Hence, trust is a bi-directional effect between participants' interactions and knowledge sharing. Interactions are quick to occur in virtual communities, e.g., emails or video conferencing, due to the rich media which have proved more effective than the lean media since rich media tools allow body-language, and expressions to enhance interactions to influence virtual sharing of knowledge (Klitmøller \& Lauring, 2013). Lack of trust reduces any opportunity for virtual sharing of resources (Lefebvre et al., 2016), making trust crucial for knowledge sharing, due to its properties of integrity, competence, and generosity (Usoro et al., 2007). Trust inspires an expectation for sharing knowledge without the threat of being taken advantage of. Hence, trust affects the virtual knowledge-sharing behaviour and interactions. $\mathrm{B}$. Wu and Zhang (2015) expressed the prominent moderating role of trust in harnessing a favourable cooperating atmosphere. The conceptual model of Lefebvre et al. (2016) expressed the mediation of trust between social interaction ties and shared knowledge in learning networks. Though Lefebvre et al. assessed the inter-relations between the three variables, the 
moderation of trust was overlooked. We extend their finding by assessing the SCT factor's inter-relations between identity, social interaction ties, trust, and shared language through the moderation of trust between virtual-community physicians' SCT and quality of the shared knowledge. Hereafter, based on this argument:

Hypothesis 5b: Physicians' trust moderates between social interaction ties and virtual-community quality in shared knowledge, so the relationship is stronger with higher levels of trust, than lower levels of trust.

\subsubsection{Trust moderation between shared language and quality in shared knowledge}

Linguistics is crucial for sharing knowledge. Persons are comfortable when interacting in a shared language (Klitmøller \& Lauring, 2013). Lefebvre et al. (2016) assessed the inter-relationship between shared language and quality in shared knowledge in e-learning with trust, as a moderator, though the moderation by trust was not assessed. Hence, we extend Lefebvre et al.'s research by assessing the inter-relations between SCT factors by assessing identity, social interaction ties, trust and shared language; through the moderation of trust between shared language and knowledge sharing for virtual-community physicians. Therefore, based on this argument,

Hypothesis 5 c: Physicians' trust moderates between shared language and virtual community's quality in shared knowledge, so the relationship is stronger with higher levels of trust, than lower levels of trust.

\subsection{Mediation of quality in shared knowledge}

\subsubsection{Mediation of quality in shared knowledge between identification and quality of decision-making}

When leaders identify with their team, theyeffectively share knowledge during group decision-making (Mathias \& Williams, 2017). For instance, since Disneyland's middle managers identify with their team, they pinpointed the correct personals possessing practical know-how and know-what for project teams. When leaders identify with employees, they help them improve knowledge sharing for enhanced commitment to the organisation (Jayasingam et al., 2017). Investors identify to comprehend know-who knowswhat knowledge for making better investment decisions, showing how knowledge sharing mediates between their identities and their decision-making capabilities (Mathias \& Williams, 2017). Such a role remains to be assessed on virtual-community physicians.

\subsubsection{Quality in shared knowledge mediates between social interaction ties and quality of decision-making}

Personal/social interactions encourage resource exchanging, e.g., SC promotes knowledge sharing, like how isolated doctors cannot exchange advice versus doctors in strong networks. SC builds value from social interactions. Knowledge spreads within interaction ties for enhanced decision-making (Patacchini \& Rainone, 2017; Yousefi-Nooraie et al., 2012). Interactions add value to the SC of resources as participants identify with each other while debating concerns as they share their knowledge for achieving quality decisions (Balkundi \& Kilduff, 2006). Though there is a widespread belief that decisions occur in the word of mouth interactions, network analysis of social ties suggest that long-lasting relations affect decisionmaking (Patacchini \& Rainone, 2017). Patacchini and Rainone assessed the effect of social interaction ties on financial decision-making and confirmed that identity, and not social interactions, influence decision-making when sharing knowledge. According to BarrosoCastro et al. (2016) interactions enable knowledgesharing behaviour for group decision-making, but are hampered during unclear interventions in social ties (Fernandez-Perez et al., 2016).

\subsubsection{Quality in shared knowledge mediates between shared language and quality of decision-making}

Globally, organisations encourage linguistic diversity, but employees gravitate to common language clusters that do not encourage informally shared knowledge. According to Ahmad (2017), common language facilitates interactions that are vital for sharing knowledge, for making innovative decisions. Today's multinational organisations hire multi-lingual employees who recognise a common corporate language. But multi-lingual groups resist such initiatives and hamper interactions in language-diverse knowledge networks. Though scholars acknowledged the mediation of the shared knowledge between SCT and innovation, e.g. (Hu \& Randel, 2014), we did not find any study that assessed the mediation of quality in shared knowledge between SCT and quality of decision-making. Based on this argument,

Hypothesis 6: Virtual community's quality in shared knowledge mediates between SCT (Identification, social interaction ties, and shared language) and quality of decision-making.

\section{Methodology}

We followed a deductive approach to confirm the relation between (1) identification, social interaction 
ties and shared language (three independent variables) $\rightarrow$ quality in shared knowledge (dependent variable), (2) the moderation of trust between, social interaction ties, identification, and shared language $\rightarrow$ quality of the shared knowledge, (3) quality in shared knowledge $\rightarrow$ quality of decision-making (another dependent variable) and (4) the mediation of quality in shared knowledge (independent variable) between identification, social interaction ties, shared language $\rightarrow$ quality of decision-making. Data were collected and analysed using a survey. The questionnaire, used for the purpose, was accompanied by (1) a cover letter describing the research aim, assuring that the study had the ethical approval of Brunel University, London and a voluntary confirmation of the confidentiality of data, followed by (2) three demographics items: (a) "Gender"

- male (124 respondents: 71.7\% response-rate) and

- females (49 respondents: $28.3 \%$ response-rate),

(b) "Work experience"

- Less than 5 years (31 respondents: 17.9\% response-rate),

- 5-10 years (19 respondents: 11\% response-rate),

- 11-15 years (14 respondents: 8.1\% response-rate)

,

- 16-20 years (24 respondents: 13.9\% responserate), and

- above 20 years (85: 49.1\% response-rate).

The remaining 23 adopted items pertained to Figure 1 model variables.

(c) "I am part of a virtual community because of a part of alan":

- Professional email list (96 respondents: 55.5\% response-rate),

- Professional group in social media, e.g., Facebook (28 respondents: 16.2\% response-rate),

- Professional platform on the internet, e.g., Sermo (44 respondents: $25.4 \%$ response-rate),

- Video conferencing for joint discussion or collaborations (5 respondents: $2.9 \%$ response-rate).

The survey included 23 adopted items to be responded to on a 5-point Likert scale: 1 (strongly disagree) to 5 (strongly agree). Two items pertained to social interaction ties, three items pertained to identity, four items pertained to trust and two items pertained to shared language: adapted from Chang et al. (2011). Six items about quality in shared knowledge were adapted from DeLone and McLean (2003). Six items about quality of decision-making, were adapted from Lin and Chang (2008).

\section{Results and analysis}

Previously analysis of the survey's demographical items was based on 173 of 204 participants. Of 204 respondents, data screening, via SPSS, led to cleaning data, removing missing values or outliers. Ten partially missing data were treated using maximum likelihood. The number of responses, 204, exceeded 200, the minimum number recommended by Wolf et al. (2013) for Structural Equation Modelling (SEM). A larger sample size would not compensate for inadequate measure reliability. Kline (2005) favours a medium sample size of 200 for SEM but opines that a larger sample would improve the findings. Table 1 depicts the survey's descriptive statistics. This study's VIFs measure ranged from 1.879 (shared language) to 3.073 (trust), i.e., the tolerance of all variables reported was above 0 , and below 10 , which dispelled the concerns over Figure 1 model.

SEM tested the hypotheses with a covariance matrix as input and maximum likelihood using Partial Least Squares, which is suitable for small sample size. Construct validity was verified with Confirmatory Factor Analysis (CFA) (Table 2). The factor loadings proved highly significant $(\mathrm{p}<0.01)$, indicating instrument's uni-dimensionality. All the composite reliabilities ranged from 0.842 to 0.949 (threshold 0.7). All the Average Variance Extracted (AVE) values exceeded 0.5 , suggesting the variance of latent factors was greater than the residual errors of the items, as depicted in Table 3, which was the results of the hierarchical moderated regression method for hypotheses testing.

\subsection{Hypotheses 1, 2, 3 and 4}

There is negative significance between identification on quality in shared knowledge where $\beta=-0.254$, $\mathrm{t}=-5.404$ and $\mathrm{p}<0.001$ (Table 3) did not support

Table 1. Mean, SD and Correlation Matrix.

\begin{tabular}{lccccccc}
\hline & Mean & Std. Dev & KSQ & Identification & SIT & SQ \\
\hline KSQ & 4.947 & 0.965 & 1 & & & & \\
Identification & 3.540 & 0.979 & $.542^{* *}$ & 1 & 1 & \\
SIT & 2.550 & 0.964 & $.367^{* *}$ & $.740^{* *}$ & $.339^{* *}$ & 1 \\
SL & 6.616 & 0.968 & $.648^{* *}$ & $.465^{* *}$ & $.480^{* *}$ & $.490^{* *}$ & 1 \\
DMQ & 4.990 & 0.970 & $.625^{* *}$ & $.631^{* *}$ & $.519^{* *}$ & $.624^{* *}$ & $.530^{* *}$ \\
Trust & 4.858 & 0.950 & $.735^{* *}$ & $.682^{* *}$ & 1 \\
\hline
\end{tabular}

Note: $p<.05,{ }^{* *} p<.01$ (2-tailed). 
Table 2. Reliability and Validity of Constructs and Measurement Items.

\begin{tabular}{|c|c|c|c|}
\hline Items (summarised) & CR & AVE & $\begin{array}{l}\text { Factor } \\
\text { Loading }\end{array}$ \\
\hline $\begin{array}{l}\text { Trust } \\
\text { CIT_1(Members in the VC will not take } \\
\text { advantage of others even when the } \\
\text { opportunity arises) } \\
\text { CIT_2 (Members in the VC would not } \\
\text { knowingly do anything to disturb the } \\
\text { conversation) } \\
\text { CIT_3 (Members in the VC would not } \\
\text { knowingly do anything to disrupt the } \\
\text { conversation) } \\
\text { CIT_4 (Members in the VC behave in } \\
\text { a consistent manner) }\end{array}$ & 0.894 & 0.549 & $\begin{array}{c}0.801 \\
0.809 \\
0.836 \\
0.83\end{array}$ \\
\hline $\begin{array}{l}\text { Identification } \\
\text { C5I_1 (I feel a sense of belonging towards } \\
\text { the VC) } \\
\text { C5I_2 (I have the feeling of togetherness } \\
\text { or closeness in the VC) } \\
\text { C5I_3 (I have a strong positive feeling } \\
\text { towards the VC) } \\
\text { C5I_4 (I am proud to be a member of the } \\
\text { VC) }\end{array}$ & 0.949 & 0.822 & $\begin{array}{l}0.929 \\
0.94 \\
0.93 \\
0.924\end{array}$ \\
\hline $\begin{array}{l}\text { Social Interaction Ties (SIT) } \\
\text { C4SI_1 (: I maintain close social } \\
\text { relationships with some members in a VC) } \\
\text { C4SI_2 (I spend lot of time interacting with } \\
\text { some members in VC on a personal level) } \\
\text { C4SI_3 (I know some members in the VC } \\
\text { on a personal level) } \\
\text { C4SI_4 (I have frequent communication } \\
\text { with some members in the VC) }\end{array}$ & 0.909 & 0.715 & $\begin{array}{l}0.89 \\
0.891 \\
0.846 \\
0.916\end{array}$ \\
\hline $\begin{array}{l}\text { Shared Language (SL) } \\
\text { C3SL_1 (The members in the VC use } \\
\text { common terms and Jargons) } \\
\text { C3SL_2 (Members in the VC use } \\
\text { understandable communication pattern } \\
\text { during the discussions) } \\
\text { C3SL_3 (Members in the VC use } \\
\text { understandable narrative forms to post } \\
\text { messages or articles) }\end{array}$ & 0.842 & 0.584 & $\begin{array}{l}0.797 \\
0.907 \\
0.873\end{array}$ \\
\hline $\begin{array}{l}\text { Knowledge Sharing Quality (KSQ) } \\
\text { C6KQ_3 (The knowledge shared by } \\
\text { members in the VC is accurate) } \\
\text { C6KQ_5 (The knowledge shared by } \\
\text { members in the VC is timely) }\end{array}$ & 0.913 & 0.84 & $\begin{array}{l}0.959 \\
0.959\end{array}$ \\
\hline $\begin{array}{l}\text { Decision-Making Quality (DMQ) } \\
\text { C2DMQ_1 (I am very certain of diagnoses } \\
\text { after my interaction with members in the } \\
\text { VC) } \\
\text { C2DMQ_2 (- I am very certain of the } \\
\text { treatment after my interaction with } \\
\text { members in the VC) } \\
\text { C2DMQ_3 (: I am very certain of health } \\
\text { benefits after my interaction with } \\
\text { members in VC) } \\
\text { C2DMQ_4 (- I am very certain of the side } \\
\text { effects after my interaction with members } \\
\text { in the VC) } \\
\text { C2DMQ_5 (I am very certain of the risks } \\
\text { after my interaction with members in the } \\
\text { VC) } \\
\text { C2DMQ_6 (I am very certain of the use of } \\
\text { evidence-based knowledge after my } \\
\text { interaction with members in the VC) }\end{array}$ & 0.921 & 0.664 & $\begin{array}{r}0.877 \\
0.881 \\
0.892 \\
0.862 \\
0.842 \\
0.709\end{array}$ \\
\hline
\end{tabular}

hypothesis 1. This result contradicts scholars who stated that when virtual-community members/peers identify with each other's values/beliefs, they begin knowledge-shared decision-making (Gossett, 2002; Park et al., 2014). However, further analysis reveals that it is apparent that when virtual-community physician-members identify with each other, their identities positively and significantly influences knowledge
Table 3. Regression Weights: (Group number 1 - Default model).

\begin{tabular}{|c|c|c|}
\hline & Path & $\beta(t) p$ \\
\hline $\mathrm{H} 1$ & $\mathrm{ID} \rightarrow \mathrm{KSQ}$ & $-0.254(-5.404)^{* * *}$ \\
\hline $\mathrm{H} 2$ & $\mathrm{SIT} \rightarrow \mathrm{KSQ}$ & 0.065 (1.354) no significance \\
\hline $\mathrm{H} 3$ & $\mathrm{SL} \rightarrow \mathrm{KSQ}$ & $0.548(11.417) * * *$ \\
\hline $\mathrm{H} 4$ & $\mathrm{KSQ} \rightarrow \mathrm{DMQ}$ & $0.368(8.762)^{* * *}$ \\
\hline Moderation & Trust $\rightarrow \mathrm{KSQ}$ & $0.72(14.694) * * *$ \\
\hline $\mathrm{H} 5 \mathrm{a}$ & Trust $\mathrm{x} I \mathrm{ID} \rightarrow \mathrm{KSQ}$ & $0.076(12.667)^{* * *}$ \\
\hline $\mathrm{H} 5 \mathrm{~b}$ & Trust $x$ SIT $\rightarrow \mathrm{KSQ}$ & $-0.032(-4.571)^{* * *}$ \\
\hline $\mathrm{H} 5 \mathrm{C}$ & Trust $\times \mathrm{SL} \rightarrow \mathrm{KSQ}$ & $-0.055(-11.000) * * *$ \\
\hline \\
\hline \multicolumn{3}{|c|}{ Partial mediation between ID $\rightarrow$ DMQ } \\
\hline $\mathrm{H} 6 \mathrm{~b}$ & $\begin{array}{l}\text { SIT } \rightarrow \text { DMQ } \\
\text { No mediation between SIT }\end{array}$ & $\begin{array}{l}0.056(1.057) \text { no significance } \\
\rightarrow \mathrm{DMQ}\end{array}$ \\
\hline $\mathrm{H} 6 \mathrm{c}$ & $\begin{array}{l}\mathrm{SL} \rightarrow \mathrm{DMQ} \\
\text { Full mediation between SL }\end{array}$ & $\begin{array}{l}0.067(1.155) \text { no significance } \\
\rightarrow \text { DMQ }\end{array}$ \\
\hline
\end{tabular}

sharing, if trust moderates. This confirmed the conclusion drawn by Gossett's and Park, et al. that there is trust-based knowledge sharing in the virtual community of physicians.

There was no effect of virtual-community physicians' social interaction ties on the quality in shared knowledge where $\beta=-0.065, t=1.354$ and $p>0.05$ (Table 3). Such an analysis does not support hypothesis 2 and the conclusion drawn by Nicolini et al. (2008) that tightly knit networks promote knowledge sharing (Chang \& Chuang, 2011; Magnier-Watanabe et al., 2010). One explanation could be that virtualcommunity physicians, who identify with peers under a common code of duty, do not need to socially interact for knowledge sharing (Riddick, 2003).

Virtual-community physicians' common language positively affects their quality in shared knowledge where $\beta=0.548, t=1.417$ and $\mathrm{p}<0.001$ (Table 3), which supports hypothesis 3 , and agrees with Jiang et al. (2015) and Mascia and Cicchetti (2011). This confirms that quality in shared knowledge aids decision-making when participants communicate in a common language (Warren et al., 2015). This makes sense why there is no effect of social interaction ties on quality in shared knowledge. It is obvious that communication in a shared language strengthens interactions for knowledge sharing.

Quality in shared knowledge positively and significantly affects the quality of decision-making since $\beta=0.368, t=8.762$ and $p<0.001$ (Table 3 ), supporting hypothesis 4, and the idea of Mazanderani et al. (2012) and Grant (2007) that the sharing of tacit/explicit knowledge enhances virtual decision-making (Mansingh et al., 2009).

\subsection{Hypotheses $5 a$ and $5 b$}

Within the context of virtual-community physicians, trust-regulated identities encourage quality knowledge sharing (Table 3), which supports hypothesis 5a and 
supports similar finding by Gossett (2002) and Park et al. (2014), though their analysis did not reveal the importance of virtual-community in such a phenomenon (Eisenberg \& Mattarelli, 2017). Moderation by trust between identification and quality in shared knowledge coincides with Eisenberg and Mattarelli (2017) and Jiang et al. (2015).

Within the context of virtual-community physicians, trust-regulated social interaction ties andquality in shared knowledge, suggesting trust, regardless of interaction, inspires knowledge sharing (Khvatova et al., 2016; Lefebvre et al., 2016; Patacchini \& Rainone, 2017). Our findings partially support hypothesis $5 \mathrm{~b}$, expressing the restraining effect of trust between interaction ties and the quality in shared knowledge.

\subsection{Hypothesis 6}

Quality in shared knowledge fully mediates between shared language and quality of decision-making, i.e., $\beta=0.3437, p<0.001, z=4.8038, \mathrm{se}=0.0716$. This is very interesting since, according to Ahmad (2017), in globally diversified language economies, shared language clusters influence knowledge sharing for inspiration led decision-making, a probable outcome of the mediation by quality in shared knowledge between SC and quality of decision-making $(\mathrm{Hu} \&$ Randel, 2014).

Quality in shared knowledge partially mediates between identification and quality of decisionmaking, i.e., $\beta=0.2147, \mathrm{p}<0.001, \mathrm{z}=3.7557$, $\mathrm{se}=0.0572$. An interesting revelation since Mathias and Williams (2017) aver that when leaders identify with each other they effectively share knowledge for quality of decision-making (Jayasingam et al., 2017; Mathias \& Williams, 2017). This supports hypothesis 6.

\section{Discussion}

Healthcare-research struggles to harness the dynamics of knowledge flow/dissemination (Yousefi-Nooraie et al., 2012). Yousefi-Nooraie et al. applied social network analysis to comprehend people's interactions for financial decision-making, Figure 1 model extends this phenomenon by assessing the mediation of quality in shared knowledge between virtual-community physicians' SC (independent variables); identification, trust, social interaction ties and shared language $\rightarrow$ quality of decision-making (dependent variable). SCT suitably assesses the role of virtual-community physicians SC on quality in knowledge shared for achieving the quality of decision-making through trust-led common understanding that offers intrinsic rewards; i.e., a sense of achievement by sharing knowledge ( $\mathrm{Hu} \&$ Randel, 2014).
The fact that our study supported the mediation of quality in shared knowledge between virtualcommunity physicians' SCT $\rightarrow$ quality of decisionmaking, our findings support scholars whose theories which built hypothesis 6 (Ahmad, 2017; Balkundi \& Kilduff, 2006; Barroso-Castro et al., 2016; FernandezPerez et al., 2016; Hu \& Randel, 2014; Jayasingam et al., 2017; Mathias \& Williams, 2017; Patacchini \& Rainone, 2017; Yousefi-Nooraie et al., 2012), as well as the role of quality in shared knowledge $\rightarrow$ quality of decision-making, thus supporting scholars whose theories helped build hypothesis 4 (Grant, 2007; Mansingh et al., 2009; Mazanderani et al., 2012).

From the perspective of Collins et al. (2015), peers achieve better work performances in virtual communities, like virtual teams, than in traditional teams. Since ample research investigated the technological aspects of virtual teams, e.g., how the application of ICT facilitates virtually shared knowledge, our findings progressed two steps forward. First, we assessed the mediation of quality in shared knowledge between virtual-community physician member's SC and quality of decision-making. Second, we assessed the role of virtual-community physician-members' quality in shared knowledge on quality of decision-making.

Our findings revealed that virtual-community SC facilitate quality in shared knowledge through identification, social interaction ties, and shared language when moderated by trust, supporting scholars who helped build theory for hypotheses (hypothesis 1) identification $\rightarrow$ quality in shared knowledge (Eisenberg \& Mattarelli, 2017; Gossett, 2002; Hu \& Randel, 2014; Jiang et al., 2015; Mazanderani et al., 2012; Song \& Phang, 2016), (hypothesis 2) social interaction ties $\rightarrow$ quality in shared knowledge (BarrosoCastro et al., 2016; Chang \& Chuang, 2011; Hu \& Randel, 2014; Komito, 2011' Magnier-Watanabe et al., 2010; Nicolini et al., 2008; Park et al., 2014), (hypothesis 3) shared language $\rightarrow$ quality in shared knowledge (Chang \& Chuang, 2011; Chiu et al., 2006; Hu \& Randel, 2014; Jiang et al., 2015; Mascia \& Cicchetti, 2011; Warren et al., 2015), (hypothesis 5a) trust moderation between identification $\rightarrow$ quality in shared knowledge (Eisenberg \& Mattarelli, 2017; Hashim \& Tan, 2015; Jiang et al., 2015; Mazanderani et al., 2012; Song \& Phang, 2016), (hypothesis 5b) trust moderation between social interaction ties $\rightarrow$ quality in shared knowledge (Khvatova et al., 2016; Lefebvre et al., 2016; B. Wu \& Zhang, 2015) and (hypothesis 5 c) trust moderation between shared language $\rightarrow$ quality in shared knowledge (Klitmøller \& Lauring, 2013; Lefebvre et al., 2016). Trust moderation between social interaction ties and quality in shared knowledge is critical, inspired by $\mathrm{Hu}$ and Randel (2014) who reported that though all SCT variables are interrelated, and each offers varying views of how SC is captured as a resource during the shared knowledge. Lastly, this 
study generalised findings within the context of USbased physicians' virtual communities.

\section{Conclusions}

This article assessed the impact of physicians' virtual communities on quality of decision-making through quality in shared knowledge by borrowing the concept of SCT to understand the role of virtual communities where resources are shared in the form of SC through quality in shared knowledge so physicians strive for achieving the quality of decision-making. We adapted a survey instrument, which was hosted on SurveyMonkey for a cross-sectional data collection from volunteering US-based SurveyMonkey virtualcommunity physicians.

The empirical evidence was the most important aspect of this study of how - and the extent virtual communities aid quality of decision-making, indicating that trust moderates to facilitate physicians' identity for increased virtual-community quality of the shared knowledge. Also, social interaction ties and shared language facilitate quality in shared knowledge while quality in shared knowledge facilitates quality of decision-making. Furthermore, quality in shared knowledge mediates between shared language $\rightarrow$ quality of decision-making, partially mediates between identification $\rightarrow$ quality of decision-making but does not mediate between social interaction ties $\rightarrow$ quality of decision-making. Such results are fascinating as many scholars discussed such roles and empirically assessed such behaviours in various contexts, but not for virtual-community physicianmembers.

\subsection{Limitations}

Our empirical findings suffer from certain limitations. Our survey collected cross-sectional data from SurveyMonkey virtual-community physicians in a single timeframe. Such data cannot be used to collect behavioural information over time, cannot assess cause-effect relationships, and the findings are, possibly, skewed by conflict of interests. Henceforth, self-selection bias and common method bias are the two of the study's limitations. However, its empirical results indicate that common method bias, using Harman's one-factor test, was at $44 \%$ variance. Though high, it is below the acceptable threshold of $50 \%$. Future research can longitudinally assess our instrument to appreciate the time-rich varying patterns of more useful information and its variables over time; to comprehend the root cause of our findings' generalisations. Furthermore, since data were collected from US-based physicians, possible cultural influences our findings, our model would be assessed in the future in other cultural contexts.

\subsection{Theoretical and practical implications}

Theoretical implications wise, model (Figure 1) is a virtual multi-dimensional decision-support collaboration system where the multi-dimensionality is reflected from SCT's three dimensions, the moderation of trust and the mediation of the quality in shared knowledge for quality of decision-making for virtualcommunity physicians. Other stakeholders, e.g., nurses/patients could enrol in virtual environments. We employed the SCT to investigate the intentions and behaviours of virtual-community informal tacit knowledge sharing. Where several scholars claimed without empirical backing that employees socially share tacit knowledge (Yang \& Farn, 2009). We produced an empirically viable model, amplifying the role of physicians' virtual communities as knowledgemanagement tools for making quality decisions when negotiated by sharing knowledge of trustworthy quality.

We addressed Mansingh et al. (2009)'s research gap, i.e., scant assessment on knowledge management tools (virtual communities on a healthcare-research topic (physicians' quality knowledge-shared-decisionmaking)) through our model (Figure 1) articulating virtual SC's influence on physicians' knowledge sharing for the quality of decision-making. Figure 1 model proves that knowledge sharing mediates when trust moderated to effectively utilise the SC for quality decision-making. Our results provide awareness of physicians' mental behaviour, through a viable framework, so future research can investigate why such behaviours vary from previous research in varying contexts.

Our findings bear theoretical implications, revealing that virtual-community physician-members whose trust mediates the quality in shared knowledge arouses the quality decision-making. Trust-led interactions aid knowledge sharing when a common language is spoken by the physicians, which promotes mutual identification. Our theory can be applied by leaders who want to nurture a trustworthy culture when seeking collaborative patient care while interacting in knowl-

edge-intensive virtual teams, through training pro-

grams that aid interpersonal skills to sustain common language incentivised virtual participations.

Our model could be practically implemented in the future, to investigate the extent virtual communities aid medical decision-making for improving the quality of health-care services. We confirm physicians' trust moderated virtual knowledge-shared-decisionmaking. So, managers should harness trust-led interactions for knowledge-shared decision-making to promote and longitudinally investigate our model with 
other stakeholders (nurses, patients, etc.) in virtual collaborative-patientcare.

\section{Disclosure statement}

No potential conflict of interest was reported by the authors.

\section{References}

Ahmad, F. (2017). Knowledge-sharing networks: Language diversity, its causes, and consequences. Knowledge and Process Management, 24(2), 139-151. https://doi.org/10. 1002/kpm.1539

Alby, F., Zucchermaglio, C., \& MattiaBaruzzo, M. (2015). Diagnostic decision making in oncology: Creating shared knowledge and managing complexity. Mind, Culture, and Activity, 22(1), 4-22. https://doi.org/10.1080/10749039. 2014.981642

Alsaad, A., Mohamad, R., \& Ismail, N. A. (2017). The moderating role of trust in business to business electronic commerce (B2B EC) adoption. Computers in Human Behavior, 68, 157-169. https://doi.org/10.1016/j.chb. 2016.11.040

Alsharo, M., Gregg, D., \& Ramirez, R. (2017). Virtual team effectiveness: The role of knowledge sharing and trust. Information $\mathcal{E}$ Management, 54(4), 479-490. https://doi. org/10.1016/j.im.2016.10.005

André, K., Baird, J., Swartling, Å. G., Vulturius, G., \& Plummer, R. (2017). Analysis of Swedish forest owners' information and knowledge-sharing networks for decision-making: Insights for climate change communication and adaptation. Environmental Management, 59(1), 885-897. https://doi.org/10.1007/s00267-017-0844-1

Aslam, M. H., Shahzad, K., Syed, A. R., \& Ramish, A. (2013). Social capital and knowledge sharing as determinants of academic performance. Journal of Behavioral \& Applied Management, 15(1), 25-41.

Bakker, M., Leenders, R. T. A. J., Gabbay, S. M., Kratzer, J., \& Van Engelen, J. M. L. (2006). Is trust really social capital? Knowledge sharing in product development projects. The Learning Organization, 13(6), 594-605. https://doi.org/10.1108/09696470610705479

Balkundi, P., \& Kilduff, M. (2006). The ties that lead: A social network approach to leadership. The Leadership Quarterly, 17(4), 419-439. https://doi.org/10.1016/j.lea qua.2006.01.001

Barroso-Castro, C., Villegas-Periñan, M. D. M., \& CasillasBueno, J. C. (2016). How boards' internal and external social capital interact to affect firm performance. Strategic Organization, 14(1), 6-31. https://doi.org/10.1177/ 1476127015604799

Chang, C.-W., Huang, H.-C., Chiang, C.-Y., Hsu, C.-P., \& Chang, C.-C. (2011). Social capital and knowledge sharing: Effects on patient safety. Journal of Advanced Nursing, 68(8), 1793-1803. https://doi.org/10.1111/j. 1365-2648.2011.05871.x

Chang, H. H., \& Chuang, -S.-S. (2011). Social capital and individual motivations on knowledge sharing: Participant involvement as a moderator. Information $\mathcal{E}$ Management, 48(1), 9-18. https://doi.org/10.1016/j.im. 2010.11.001

Chen, Y., Yan, X., Fan, W., \& Gordon, M. (2015). The joint moderating role of trust propensity and gender on consumers' online shopping behavior. Computers in Human
Behavior, 43, 272-283. https://doi.org/10.1016/j.chb. 2014.10.020

Chiu, C.-M., Hsu, M.-H., \& Wang, E. T. (2006).

Understanding knowledge sharing in virtual communities: An integration of social capital and social cognitive theories. Decision Support Systems, 42(3), 1872-1888. https://doi.org/10.1016/j.dss.2006.04.001

Choi, Y. (2016). The impact of social capital on employees' knowledge-sharing behavior: An empirical analysis of U.S. federal agencies. Public Performance $\mathcal{E}$ Management Review, 39(2), 381-405. https://doi.org/10. 1080/15309576.2015.1108795

Chumg, H.-F., Seaton, J., Cooke, L., \& Ding, W.-Y. (2016). Factors affecting employees' knowledge-sharing behaviour in the virtual organisation from the perspectives of well-being and organisational behaviour. Computers in Human Behavior, 64, 432e448. https://doi.org/10.1016/j. chb.2016.07.011

Collins, N., Chou, Y.-M., Warner, M., \& Rowley, C. (2015). The international journal of human resource human factors in East Asian virtual teamwork: A comparative study of Indonesia, Taiwan and Vietnam. The International Journal of Human Resource Management, 28(10), 1475-1498. https://doi.org/10.1080/09585192.2015. 1089064

DeLone, W. H., \& McLean, E. R. (2003). The DeLone and McLean model of information systems success: A tenyear update. Journal of Management Information Systems, 19(4), 9-30. https://doi.org/10.1080/07421222. 2003.11045748

Dijk, A. V., Hendriks, P., \& Romo-Leroux, I. (2016). Knowledge sharing and social capital in globally distributed execution. Journal of Knowledge Management, 20(2), 327-343. https://doi.org/10.1108/JKM-07-2015-0268

Eisenberg, J., \& Mattarelli, E. (2017). Building bridges in global virtual teams: The role of multicultural brokers in overcoming the negative effects of identity threats on knowledge sharing across subgroups. Journal of International Management, 23(4), 399-411. https://doi. org/10.1016/j.intman.2016.11.007

Fahey, R., Vasconcelos, A. C., \& Ellis, D. (2007). The impact of rewards within communities of practice: A study of the SAP online global community. Knowledge Management Research $\mathcal{E}$ Practice, 5(3), 186-198. https://doi.org/10. 1057/palgrave.kmrp.8500140

Fan, Y.-W., \& Wu, -C.-C. (2011). The role of social capital in knowledge sharing: A meta-analytic review. Hawaii, HICSS - IEEE Advanced Technology for Humanity.

Fernandez-Perez, V., Garcia-Morales, V. J., \& Pulles, D. C. (2016). Entrepreneurial decision-making, external social networks and strategic flexibility: The role of CEOs' cognition. European Management Journal, 34(3), 296e309. https://doi.org/10.1016/j.emj.2015.12.002

Garcia-Perez, A., Shaikh, S. A., Kalutarage, H. K., \& Jahantab, M. (2015). Towards a knowledge-based approach for effective decision-making in railway safety. Journal of Knowledge Management, 19(3), 641-659. https://doi.org/10.1108/JKM-02-2015-0078

Gossett, L. M. (2002). Kept at arm's length: Questioning the organizational desirability of member identification. Communication Monographs, 69(4), 385-404. https:// doi.org/10.1080/03637750216548

Grant, K. A. (2007). Tacit knowledge revisited - We can still learn from Polanyi. The Electronic Journal of Knowledge Management, 5(2), 173-180. www.ejkm.com

Han, T.-S., Chiang, -H.-H., \& Chang, A. (2010). Employee participation in decision making, psychological 
ownership and knowledge sharing: Mediating role of organizational commitment in Taiwanese high-tech organizations. The International Journal of Human Resource Management, 21(12), 2218-2233. https://doi. org/10.1080/09585192.2010.509625

Hasan, H., \& Crawford, K. (2007). Knowledge mobilisation in communities through socio-technical systems. Knowledge Management Research E Practice, 5(4), 237 247.https://doi.org/10.1057/palgrave.kmrp. 8500144

Hashim, K. F., \& Tan, F. B. (2015). The mediating role of trust and commitment on members' continuous knowledge sharing intention: A commitment-trust theory perspective. International Journal of Information Management, 35(2), 145-151. https://doi.org/10.1016/j. ijinfomgt.2014.11.001

Ho, M. H.-W., Ghaur, P. N., \& Larimo, J. A. (2018).

Institutional distance and knowledge acquisition in international buyer-supplier relationships: The moderating role of trust. Asia Pacific Journal of Management, 35(2), 427-447. https://doi.org/10.1007/s10490-017-9523-2

Homel, C., Benyoucef, M., \& Kuziemsky, C. (2012). Determinants of participation in an Inuit online community of practice. Knowledge Management Research $\mathcal{E}$ Practice, 10(1), 41-54. https://doi.org/10.1057/kmrp. 2011.15

Hu, L., \& Randel, A. E. (2014). Knowledge sharing in teams: Social capital, extrinsic incentives, and team innovation. Group E Organization Management, 39(2), 213-242. https://doi.org/10.1177/1059601114520969

Hung, S.-Y., Durcikova, A., Lai, H.-M., \& Lin, W.-M. (2011). The influence of intrinsic and extrinsic motivation on individuals' knowledge sharing behavior. International Journal of Human-Computer Studies, 69(6), 415-427. https://doi.org/10.1016/j.ijhcs.2011.02.004

Jayasingam, S., Govindasamy, M., \& Singh, S. K. G. (2017). Instilling affective commitment: Insights on what makes knowledge workers want to stay. Management Research Review,39(3), 266-288.https://doi.org/10.1108/MRR-032014-0060

Jiang, W., Gu, Q., \& Wang, G. G. (2015). To guide or to divide: The dual-side effects of transformational leadership on team innovation. Journal of Business and Psychology, 30(4), 677-691. https://doi.org/10.1007/ s10869-014-9395-0

Khvatova, T., Block, M., Zhukov, D., \& Lesko, S. (2016). How to measure trust: The percolation model applied to intra-organisational knowledge sharing networks. Journal of Knowledge Management, 20(5), 918-935. https://doi.org/10.1108/JKM-11-2015-0464

Kline, R. B. (2005). Principles and practice of structural equation modeling (2rd ed.). The Guilford Press.

Klitmøller, A., \& Lauring, J. (2013). When global virtual teams share knowledge: Media richness, cultural difference and language commonality. Journal of World Business, 48(3), 398-406. https://doi.org/10.1016/j.jwb. 2012.07.023

Komito, L. (2011). Social Media and Migration: Virtual community 2.0. Journal of the American Society for Information Science and Technology, 62(6), 1075-1086. https://doi.org/10.1002/asi.21517

$\mathrm{Ku}, \mathrm{M}$. (2019). Similarity-dissimilarity and social capital in research knowledge networks: Explaining knowledge sharing in academic institutions. Knowledge Management Research \& Practice, 17(3), 264-275. https://doi.org/10.1080/14778238.2019.1595986

Lefebvre, V. M., Sorenson, D., Henchion, M., \& Gellynck, X. (2016). Social capital and knowledge sharing performance of learning networks. International Journal of Information Management, 36(4), 570-579. https://doi. org/10.1016/j.ijinfomgt.2015.11.008

Lin, C., \& Chang, S. (2008). A relational model of medical knowledge sharing and medical decision-making quality. International Journal of Technology Management, 43(4), 320-348. https://doi.org/10.1504/IJTM.2008.020554

Lin, T. C., Lai, M. C., \& Yang, S. W. (2016). Factors influencing physicians' knowledge sharing on web medical forums. Health Informatics Journal, 22(3), 594-607. https:// doi.org/10.1177/1460458215576229

Magnier-Watanabe, R., Yoshida, M., \& Watanabe, T. (2010). Social network productivity in the use of SNS Journal of Knowledge Management, 14(6), 910-927. https://doi.org/10.1108/13673271011084934

Makary, M., 2018. Johns Hopkins study suggests medical errors are third-leading cause of death in U.S.Retrieved September 12, 2018, from https://hub.jhu.edu/2016/05/ 03/medical-errors-third-leading-cause-of-death/.

Malgonde, O., \& Bhattacherjee, A. (2014). Innovating using big data: A social capital perspective. Association for Information Systems.

Mansingh, G., Osei-Bryson, K.-M., \& Reichgelt, H. (2009). Issues in knowledge access, retrieval and sharing - Case studies in a Caribbean health sector. Expert Systems with Applications, 36(2), 2853-2863. https://doi.org/10.1016/j. eswa.2008.01.03

Mascia, D., \& Cicchetti, A. (2011). Physician social capital and the reported adoption of evidence-based medicine: Exploring the role of structural holes. Social Science $\mathcal{E}$ Medicine, 72(5), 798-805. https://doi.org/10.1016/j.socs cimed.2010.12.011

Mathias, B. D., \& Williams, D. W. (2017). The Impact of Role Identities on Entrepreneurs' Evaluation and Selection of Opportunities. Journal of Management, 43 (3), 892-918.https://doi.org/10.1177/0149206314544747

Mazanderani, F., Locock, L., \& Powell, J. (2012). Being differently the same: The mediation of identity tensions in the sharing of illness experiences. Social Science $\mathcal{E}$ Medicine, 74(4), 546e553. https://doi.org/10.1016/j.socs cimed.2011.10.036

Mikovic, R., Petrovic, D., Mihic, M., Obradovic, V., \& Todorovic, M. (2019). Examining the relationship between social capital and knowledge usage in the nonprofit industry. Knowledge Management Research $\mathcal{E}$ Practice, 17(3), 328-339. https://doi.org/10.1080/ 14778238.2019 .1638740

Nahapiet, J., \& Ghoshal, S. (1998). Social capital, intellectual capital, and the organizational advantage. The Academy of Management Review, 23(2), 242-266. https://doi.org/ 10.5465/amr.1998.533225

Nemati, H. R., Steiger, D. M., Iyer, L. S., \& Herschel, R. T. (2002). Knowledge warehouse: An architecture of knowledge management, decision support, artificial intelligence and data warehousing. Decision Support Systems, 33(2), 143-161. https://doi.org/10.1016/S0167-9236(01)00141-5

Nicolini, D., Powell, J., Conville, P., \& Martinez-Solano, L. (2008). Managing knowledge in the healthcare sector. A review. International Journal of Management Reviews, 10 (3), 245-263. https://doi.org/10.1111/j.1468-2370.2007. 00219.x

Nov, O., Ye, C., \& Kumar, N. (2012). A social capital perspective on meta-knowledge contribution and social computing. Decision Support Systems, 53(1), 118-126. https://doi.org/10.1016/j.dss.2011.12.009

Park, J. H., Gu, B., Leung, A. C. M., \& Konana, P. (2014). An investigation of information sharing and seeking 
behaviors in online investment communities. Computers in Human Behavior, 31, 1-12. https://doi.org/10.1016/j. chb.2013.10.002

Patacchini, E., \& Rainone, E. (2017). Social ties and the demand for financial services. Journal of Financial Services Research, 52(1-2), 5-88. https://doi.org/10. 1007/s10693-017-0279-0

Pinheiro, A. L. S., Andrade, K. T. S., Silva, D. D. O., Zacharias, F. C. M., Gomide, M. F. S., \& Pinto, I. C. (2016). Health management: The use of information system and knowledge sharing for the decision making process. Texto Contexto Enferm, 25(3), 2-9. https://doi. org/10.1590/0104-07072016003440015

Pinjani, P., \& Palvia, P. (2013). Trust and knowledge sharing in diverse global virtual teams. Information $\mathcal{E}$ Management, 50(4), 144-153. https://doi.org/10.1016/j. im.2012.10.002

Puschner, B., Steffen, S., Slade, M., Kaliniecka, H., Maj, M., Fiorillo, A., Munk-Jørgensen, P., Larsen, J. I., Égerházi, A., Nemes, Z., Rössler, W., Kawohl, W., \& Becker, T. (2010). Clinical decision making and outcome in routine care for people with severe mental illness (CEDAR): Study protocol viewing options: Abstract. BMC Psychiatry, 10(1), 90. https://doi.org/10.1186/ 1471-244X-10-90

Razzaque, A., \& Eldabi, T. (2015). Assessing the role of physicians' knowledge shared decision making in a virtual community. Enterprise Information Management, 26(5), 500-515. https://doi.org/10.1108/ JEIM-07-2013-0047

Razzaque, A., \& Eldabi, T. (2018). Assessing the impact of physicians' virtual communities on their medical decision making quality. Hawaii, University of Hawaii at Manoa. Riddick, F. A. (2003). The code of medical ethics of the American Medical Association. The Ochsner Journal, 5 (2), 6-10.

Roberts, J. (2006). Limits to Communities of Practice. Journal of Management Studies,43(3), 623-639.

Rosendaal, B., \& Bijlsma-Frankema, K. (2015). Knowledge sharing within teams: Enabling and constraining factors. Knowledge Management Research \& Practice, 13(3), 235-247. https://doi.org/10.1057/kmrp.2013.45

Schuele, M., Widmer, T., Premm, M., Criegee-Rieck, M., \& Wickramasinghe, N. (2015). Using a multiagent organizational approach to improve knowledge provision for shared decision making in patient-physician relationships: An example from Germany. Health and Technology, 5(1), 13-23. https://doi.org/10.1007/s12553015-0102-6

Smith, C. (2017). An analysis of structural social capital and the individual's intention to share tacit knowledge using reasoned action theory. The Journal of Applied Business Research, 33(3), 475-488. https://doi.org/10.19030/jabr. v33i3.9940

Song, P., \& Phang, C. W. (2016). Promoting continuance through shaping members' social identity in knowledgebased versus support/advocacy virtual communities. IEEE Transaction On Engineering Management, 63(1), 16-26. https://doi.org/10.1109/TEM.2015.2488698
Stets, J. E., \& Serpe, R. T. (2016). New directions in identity theory and research. Oxford University Press.

Tsai, W., \& Ghoshal, S. (1998). Social capital and value creation: The role of intrafirm networks. The Academy of Management Journal, 41(4), 464-476. doi: 10.2307/ 257085

Usoro, A., Sharratt, M. W., Tsui, E., \& Shekhar, S. (2007). Trust as an antecedent to knowledge sharing in virtual communities of practice. Knowledge Management Research E Practice, 5(3), 199-212. https://doi.org/10. 1057/palgrave.kmrp.8500143

Warren, A. M., Sulaiman, A., \& Jaafar, N. I. (2015). Understanding civic engagement behaviour on Facebook from a social capital theory perspective. Behaviour \& Information Technology, 34(2), 163-175. https://doi.org/10.1080/0144929X.2014.934290

Widén-Wulff, G., \& Ginman, M. (2004). Explaining knowledge sharing in organizations through the dimensions of social capital. Journal of Information Science, 30(5), 448-458. https://doi.org/10.1177/0165551504046997

Wolf, E. J., Harrington, K. M., Clark, S. L., \& Miller, M. W. (2013). Sample size requirements for structural equation models: An evaluation of power, bias, and solution propriety. SAGE, 73(6), 913-934. doi: 10.1177/ 0013164413495237

Wu, B., \& Zhang, C. (2015). Trust evaluation for interorganization knowledge sharing via the e-learning community. The Electronic Library, 33(3), 400-416. https://doi.org/10.1108/EL-08-2013-0140

Wu, W.-L., \& Lee, Y.-C. (2016). How to make a knowledge-sharing group: A group social capital. Personnel Review, 45(3), 523-538. https://doi.org/10. 1108/PR-12-2013-0227

Xiang, C., Lu, Y., \& Gupta, S. (2013). Knowledge sharing in information system development teams: Examining the impact of shared mental model from a social capital theory perspective. Behaviour $\mathcal{E}$ Information Technology, 32(20), 1024-1040. https://doi.org/10.1080/ 0144929X.2012.745901

Yang, S.-C., \& Farn, C.-K. (2009). Social capital, behavioural control, and tacit knowledge sharing - A multi-informant design. International Journal of Information Management, 29(3), 210-218. https://doi.org/10.1016/j. ijinfomgt.2008.09.002

Yen, Y.-F., Tseng, J.-F., \& Wang, H.-K. (2015). The effect of internal social capital on knowledge sharing. Knowledge Management Research E Practice, 13(2), 214-224. https:// doi.org/10.1057/kmrp.2013.43

Yousefi-Nooraie, R., Dobbins, M., Brouwers, M., \& Wakefield, P. (2012). Information seeking for making evidence-informed decisions: A social network analysis on the staff of a public health department in Canada. BMC Health Services Research, 12, 118-134. https://doi. org/10.1186/1472-6963-12-118

Yu, T., Hao, J.-X., Dong, X.-Y., \& Khalifa, M. (2013). A multilevel model for effects of social capital and knowledge sharing in knowledge-intensive work teams. International Journal of Information Management, 33(5), 780-790. https://doi.org/10.1016/j.ijinfomgt.2013.05.005 